\title{
Preparation, characterization, and radiation absorption study of bentonite clay included soft chewable lozenge formulations
}

\author{
Rukiye Sevinç Özakar ${ }^{1 *}$, Medya Kara² ${ }^{2}$ Adem Maman ${ }^{3}$ \\ ${ }^{1}$ Department of Pharmaceutical Technology, Faculty of Pharmacy, Atatürk University, Erzurum, Turkey \\ ${ }^{2}$ Faculty of Pharmacy, Atatürk University, Erzurum, Turkey \\ ${ }^{3}$ Department of Nuclear Medicine, Faculty of Medicine, Atatürk University, Erzurum, Turkey
}

\begin{tabular}{|c|c|}
\hline \multicolumn{2}{|c|}{ ARTICLE INFO } \\
\hline \multicolumn{2}{|c|}{ Article history: } \\
\hline Received & 22 Sep 2020 \\
\hline Revised & 24 Dec 2020 \\
\hline Accepted & 15 Jan 2021 \\
\hline Online & 07 May 2021 \\
\hline Published & 10 May 2021 \\
\hline \multicolumn{2}{|l|}{ Keywords: } \\
\hline \multicolumn{2}{|c|}{ Bentonite } \\
\hline \multicolumn{2}{|c|}{ Characterization } \\
\hline \multicolumn{2}{|c|}{ Lozenge } \\
\hline \multicolumn{2}{|c|}{ Radiation absorption } \\
\hline \multicolumn{2}{|c|}{ Technetium } \\
\hline \multicolumn{2}{|c|}{$\begin{array}{l}{ }^{*} \text { Corresponding author: } \\
\text { rukiyeso@atauni.edu.tr }\end{array}$} \\
\hline
\end{tabular}

\begin{abstract}
A B S T R A C T
Lozenges are renewed popularity as a means of administering many different drugs and may be considered as alternatives to current dosage forms. Lozenges are solid/semi-solid dosage forms that can contain one or more active ingredients, generally prepared as aromatized and sweetened, dissolve or dispersed in the mouth, chewable, absorbable. They can be used in local treatment of mouth and throat infections or irritation to slowly release a fixed amount of drug into the oral cavity or cover the throat tissues with the drug solution, and sometimes to achieve systemic effects when the drug is well absorbed through the buccal membranes or chewed and swallowed. Recently, soft lozenges and chewable lozenges have been re-introduced into the pharmacy and their popularity is increased. At present, we are all exposed to a certain level of radiation. Scientific evidence from past events has demonstrated that any major uncontrolled release of radiation could be harmful and warrants immediate response to assess and minimize public health risks. Bentonite is a natural highly colloidal clay and is used for protection from radiation. This study aims to prepare soft chewable lozenge formulations containing different bentonite doses by using 2 different preparation techniques (hand-rolling and molding techniques), to make quality control tests of the lozenges and to determine the degree of radiation absorption.
\end{abstract}

This is an open-access article licensed under the Creative Commons Attribution 4.0 International License (CC-BY). (c)) EY

\section{INTRODUCTION}

Oral dosage forms are very diverse and have many advantages over other dosage forms. Oral medication is the easiest way to administer therapeutic agents to achieve a systemic effect since it can be used without any help. In the use of oral dosage forms, it is always the most preferred form of medicine due to its high patient compliance, availability of various formulations, and easy transportation. They are economical and safe for the patient. However, it still has some disadvantages. They are not suitable dosage forms for children and infants, especially for patients with chronic vomiting problems and gastrointestinal disorders such as diarrhea, constipation, ulcer, hyperacidity. Their use is not preferred in cases requiring urgent intervention and in patients with loss of consciousness [1].

Lozenges are renewed popularity as a means of administering many different drugs and may be considered as alternatives to current dosage forms. Lozenges are solid/semi -solid dosage forms that can contain one or more active ingredients, generally prepared as aromatized and sweetened, dissolve or dispersed in the mouth, chewable, absorbable. They are also called troches or pastilles [2]. They can be used in local treatment of mouth and throat infections or irritation to slowly release a fixed amount of drug into the oral cavity or cover the throat tissues with the drug solution, and sometimes to achieve systemic effects when the drug is well absorbed through the buccal membranes or chewed and swallowed $[1,3,4]$. In general, the absorption time of the oral lozenge is considered to be about 30 minutes in solid absorbable lozenges, but the dissolution and absorption of the lozenge may vary depending on the patient's absorption state. Also, suction and subsequent continuous production of saliva can cause the drug to be diluted and accidentally swallowed $[1,4,5]$. As a result, high variations can occur in the amount of medication given with each application of the lozenge. Absorption and subsequent saliva production may also cause the drug to be diluted and accidentally swallowed [1]. Lozenge formulations have many advantages: It is convenient and easy to use for pediatric and geriatric patients with difficulty swallowing. It has a pleasant taste and is enough to stay in the oral cavity for a while to bring out a certain effect. It does not require water requirement for patients to use. It can be prepared by a pharmacist in a pharmacy for a small amount of substance and for a short time $[4,6,7]$. Besides, there are disadvantages such as the tendency to accidentally use as candy by children, risk of swallowing hard lozenges for children under 6 years of age, 
and the uncommon distribution of the drug in saliva for local treatment $[4,6]$. Nowadays, there are many types of lozenges such as chewable lozenges, compressed lozenges, hard candy lozenges, center filled hard lozenges, soft lozenges. Recently, soft lozenges and chewable lozenges have been re-introduced into the pharmacy and their popularity is increased. The soft lozenges generally have a polyethylene glycol base and the chewable lozenges have a glycerinated gelatin base. These usually are chewable and this chewability is a means of delivering the product to the gastrointestinal tract for systemic absorption. Commercial lozenges are made by a tableting machine using high compression pressures and by moulding. Also, the hand-rolling technique is used for soft lozenges or in small scale formulations $[1,4,6]$.

At present, we are all exposed to a certain level of radiation. Radiation exposure of humans can be studied in many branches for research and control. The National Council on Radiation Protection and Measurements of the United States (NGRP, 1971) describes radiation as natural radiation, radiation applied in research on human subjects, radiation from medical procedures, occupational irradiation, and man-made environmental radiation. Also, radiation exposures are usually categorized as internal or external in reference to the location of the source relative to the irradiated individual $[8,9]$.

Natural radiation sources are broadly categorized into cosmic, terrestrial (e.g., earth's crust, soil, and construction material, radon from rocks), and internal radiation. Unfortunately, human exposure to natural radiation is not controllable. Also, people are routinely exposed to manmade radiation from nuclear medical diagnostics (e.g., X-ray and Computerized Tomography scans) and treatment procedures, nuclear power plants, commercial flying, and even smoking. However, scientific evidence from past events has demonstrated that any major uncontrolled release of radiation could be harmful and warrants immediate response to assess and minimize public health risks. However, exposure to man-made radiation can be controlled by taking precautions $[8,10]$. The rapid development in science technology causes radiation widely used in many research areas, which have increased people's exposure to different kinds of radiation. Three main methods are usually utilized for protection from radiation: time, distance, and shielding. Among the three methods, shielding is the most important protection method. Thus, shielding materials become very important. Different radiation protection materials (lead, copper, bismuth, steel, concretes and organic compounds such as oils, paraffins, plastics and rubber) have been developed to reduce the damage caused by radiation to the human body. But, natural materials like bentonite clay can be used as shelters from nuclear waste because of its availability and low cost [11]. Clays are common ingredients used in pharmaceutical products as excipients and active substances [12]. The ability of clay minerals to adsorb and desorb organic molecules is well known and makes them very attractive for pharmaceuticals [13]. All bentonites are from the montmorillonite group of clay minerals and are an aluminum hydrosilicate with soft colloidal property. Montmorillonite minerals show a three-layered structure and this is their characteristic feature. Water and organic molecules enter between these layers and cause the structure to expand/swell, so it is frequently used as a viscosity enhancer with its large surface area [14]. Bentonite is a natural highly colloidal clay mainly composed of montmorillonite that is abundant and non-expensive. The reliability of bentonite in humans and animals has been proven by studies. Bentonite does not influence serum concentrations of vitamins and nutrients in humans [15]. Bentonite clay has been shown to act as a detoxifying agent. This property is referred to its cationic nature, which leads to the absorption of negative charge toxins. Also, it is generally used in the form of blocks as an ideal backfill material for a high-level radioactive waste tank in deep rocks $[15,16]$. Bentonite is known to inhibit diffusive transport of most radionuclides due to its good absorption properties. There are many studies on the absorption of radioactive materials such as uranium, cesium, nickel and lead by bentonite [16,17]. Bentonite is frequently used for protection from gamma radiation. Bentonite has been proven to be highly effective against gamma radiation in the studies of Hager et al. [11] and Ishii et al.[18].

In the literature evaluation, there is no dosage form of bentonite prepared for protection from radiation. This work we have done is the first. But, in many countries, the drinkable form of food-grade bentonite is sold for the protection from toxins and radiation [19]. Based on the information given above, it was decided to study the bentonite lozenge formulation, which is a dosage form that can be easily used by humans. So, this study aims to prepare soft chewable lozenge formulations containing different bentonite doses by using 2 different preparation techniques (hand-rolling and molding techniques), to make quality control tests (determination of organoleptic properties, weight variation, diameter-thickness, friability test, dispersion time) of the lozenges with optimum properties and to determine the degree of radiation absorption. Technetium $\left({ }^{99 \mathrm{~m}} \mathrm{Tc}\right)$ was used in the radiation absorption study. ${ }^{99 \mathrm{~m}} \mathrm{Tc}$ emits gamma radiation and bentonite absorbs gamma radiation [20]. Gamma radiation is one of the main types of nuclear radiation, which have to be considered. In this study, the absorption ability of bentonite in lozenge form is evaluated.

\section{MATERIALS AND METHODS}

\subsection{Materials}

Pharmaceutical grade bentonite was obtained as a gift from Galenik Ecza (İzmir, Turkey). Gelatin and carboxymethylcellulose sodium (NaCMC) were kindly supplied by Gelita (Germany) and Doğa İlaç (Turkey), respectively. All other chemicals were in analytical or pharmaceutical grade.

\subsection{Preparation of Bentonite Included Soft Chewable Lozenges}

Lozenges were prepared by molding and hand-rolling techniques [1]. Bentonite and all excipients were mixed in certain proportions using a magnetic stirrer in accordance with the technique. Bentonite was added last during the preparation. Prepared lozenges were wrapped with wax paper and put in well-closed containers. 
In the hand-rolling technique, the prepared mixture was placed on a glass table and the mixture was made homogeneous with the help of a spatula by adding bentonite last. The mixture was then rolled by hand to form a long strip, and it was measured with a ruler and cut with a knife to contain the desired dose. The lozenge formulations prepared with this technique were designed to contain $1.5 \mathrm{~g}$ and $2 \mathrm{~g}$ bentonite doses.

In the molding technique, the prepared mixture was poured in certain amounts into the molds, the inner walls of which were covered with starch, to prevent sticking to the mold, and cooled to room temperature and formed. The lozenge formulations prepared by this technique were designed to contain bentonite at a dose of $0.25 \mathrm{~g}$ and $0.5 \mathrm{~g}$. Ingredients of all formulations prepared with both molding and hand-rolling technique are given in Table 1.

Table 1. Ingredients of all formulations

\begin{tabular}{lcccc}
\hline $\begin{array}{l}\text { Ingredients } \\
\text { weights (g) }\end{array}$ & \multicolumn{2}{c}{ Molding Technique } & \multicolumn{2}{c}{$\begin{array}{c}\text { Hand-rolling } \\
\text { Technique }\end{array}$} \\
\cline { 2 - 5 } & M0.25 & M0.5 & H1.5 & H2 \\
\hline Bentonite & 0.25 & 0.50 & 1.50 & 2.00 \\
Citric acid & 0.10 & 0.10 & 0.10 & 0.10 \\
Menthol & 0.10 & 0.10 & 0.10 & 0.10 \\
Peppermint oil & 0.05 & 0.05 & 0.05 & 0.05 \\
Glycerin & 0.25 & 0.25 & 0.25 & 0.25 \\
Methyl paraben & 0.01 & 0.01 & 0.01 & 0.01 \\
Sodium saccharin & 0.10 & 0.10 & 0.10 & 0.10 \\
NaCMC & 0.20 & 0.20 & 0.25 & 0.25 \\
Gelatin & 0.80 & 0.80 & - & - \\
PEG 4000 & 0.20 & 0.20 & - & - \\
Distilled water & 4.00 & 5.50 & 2.00 & 2.25 \\
Carmine & q.s. & - & - & - \\
Toluidin blue & - & q.s. & - & - \\
Fast green FCF & - & - & q.s. & - \\
Eosine & - & - & - & q.s. \\
\hline
\end{tabular}

The same procedures were applied for lozenges that do not contain bentonite (blank lozenges), and the only bentonite was not added into the mixture. "Fast Green FCF" dye and "carmine" were used as a dye in the lozenges prepared by hand-rolling and molding technique, respectively. Prepared lozenges were wrapped with wax paper and put in boxes.

\subsection{Characterization of Soft Chewable Lozenges}

\subsubsection{Organoleptic properties}

The prepared lozenges were evaluated for its organoleptic properties like taste, odour, colour, softness, chewability, and shape [21].

\subsubsection{Weight variation}

For weight variation, 20 lozenges were taken and weighed each individually on a precision balance. After the average weight of the lozenges was found, the deviation values of each lozenge from the average weight were found in $\%$. The weight variation of any lozenge should not exceed $10 \%$ according to the USP limit [22].

\subsubsection{Diameter and thickness}

20 lozenges were taken and each one was measured with a vernier caliper for their diameter and thickness. The average diameter-thickness values in $\mathrm{mm}$ and standard deviation of lozenges were found [22].

\subsubsection{Friability}

10 lozenges were taken and all were weighed together on precision balances. The weighed lozenges were rotated for 4 minutes in the friabilitor at $25 \mathrm{rpm}$ per minute and the friability values were calculated in $\%$. The friability value should not exceed $1 \%$ [23].

\subsubsection{Disintegration time}

6 lozenges were taken and put into a disintegrator. The disintegration time was determined in $\mathrm{pH} 6.8$ artificial saliva fluid at $37^{\circ} \mathrm{C}$ and $100 \mathrm{rpm}$ [23]. Artificial saliva (at $\mathrm{pH} 6.75$ ) was prepared according to the following formulation [24]:

$R x$

Disodium Hydrogen Phosphate $2.382 \mathrm{~g}$

Potassium Dihydrogen Phosphate $0.190 \mathrm{~g}$

Sodium Chloride $\quad 8.000 \mathrm{~g}$

Ultrapure water q.s. $1 \mathrm{~L}$

\subsection{Determination of Radiation Absorption}

This study was carried out in Atatürk University Faculty of Medicine, Department of Nuclear Medicine. 4 pieces of lozenges containing bentonite, which have optimum properties, were exposed to ${ }^{99 \mathrm{~m}} \mathrm{Tc}$ radiation (starting intensity is $497 \mathrm{mCi}$ ) for the specified time in a closed steel case. The ${ }^{99 \mathrm{~m}} \mathrm{Tc}$ half-life is 6 hours. Then, the radiation in the lozenges was measured with an appropriate measuring device (well counter) at the 6th hour, and the radiation absorption efficiency of the lozenges containing bentonite was evaluated by calculating the average of radiation $(\mathrm{mCi})$ per lozenge.

All results were given with standard deviation value. Statistical analysis was made by using One way ANOVA test through the SPSS Statistics 20.0 (SPSS Inc., Chicago, Illinois, USA) program. In the evaluation of the results obtained, data with a P-value of less than $0.05(\mathrm{p}<0.05)$ were considered as significant.

Table 2. Organoleptic properties of bentonite included soft chewable lozenges

\begin{tabular}{lcccc}
\hline \multirow{2}{*}{ Organoleptic properties } & \multicolumn{2}{c}{ Molding Technique } & \multicolumn{2}{c}{ Hand-rolling Technique } \\
\cline { 2 - 5 } & M0.25 & M0.5 & H1.5 & H2 \\
\hline Taste & Sweet & Sweet & Sweet & Sweet \\
Odour & Menthol-Mint & Menthol-Mint & Menthol-Mint & Menthol-Mint \\
Colour & Pink & Purple & Green & Light Orange \\
Softness & Soft & Soft & Medium Hard & Medium Hard \\
Chewability & Good & Good & Good & Good \\
Shape & Round & Square & Cylinder & Cylinder \\
\hline
\end{tabular}




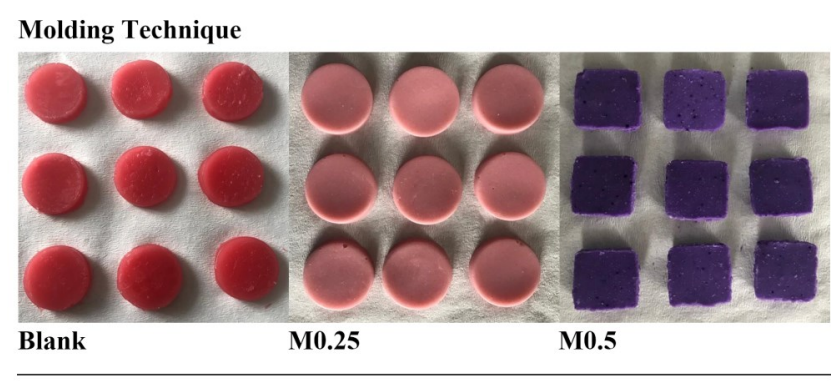

Hand-rolling Technique

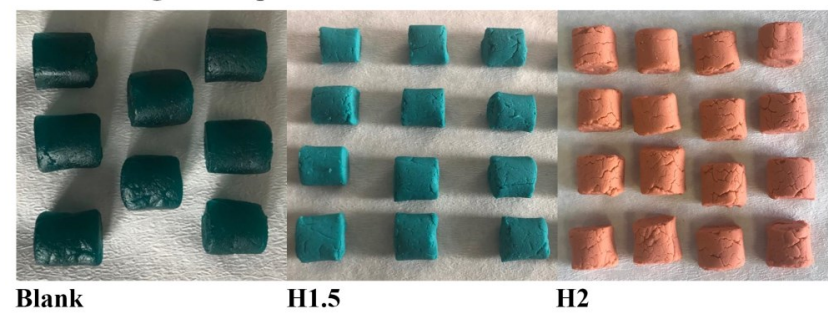

Figure 1. Images of soft chewable lozenges

\section{RESULTS AND DISCUSSION}

\subsection{Preparation of Bentonite Included Soft Chewable Lozenges}

Bentonite included lozenges in 4 different doses and were successfully prepared with the blank ones by using molding and hand-rolling techniques. All the formulations showed good physical appearance. The gelatin used in the molding method as binder enabled the lozenges containing low-dose bentonite to keep their shape due to its gelling feature [25]. Images of bentonite included and blank lozenges are given in Figure 1.

\subsection{Characterization of Soft Chewable Lozenges}

\subsubsection{Organoleptic properties}

Organoleptic properties are optimized so that a patient can adapt to chewing. The prepared lozenges are formulated in accordance with their purpose in terms of taste, odour, colour, softness, chewability, and shape properties. Organoleptic properties are at a level acceptable to the patient. Organoleptic properties of bentonite included lozenges are given in Table 2.

\subsubsection{Weight variation, diameter, thickness, friability, and disintegration time}

The weight variation, diameter, thickness, friability, and disintegration time of bentonite included lozenges were evaluated and the results are given in Table 3. The weight variation, diameter, and thickness values were given as average \pm standard deviation. All the formulations were found to show acceptable weight, diameter, and thickness. The percentage of weight variation was within the USP limits and the values varied between $-4.83 \%$ and $3.89 \%$ for $\mathrm{M} 0.25$, $5.07 \%$ and $4.37 \%$ for $\mathrm{M} 0.5,-1.28 \%$ and $0.41 \%$ for $\mathrm{H} 1.5$, and $-1.74 \%$ and $2.41 \%$ for H2. Diameter and thickness values are within acceptable limits in terms of easy chewing. Only one formulation (M0.5) exceeded the $1 \%$ limit in the friability test. When all formulations are compared, it is seen that formulation M0.5 has the most water. This excess water made the lozenges more fragile and sticky, so this formulation was stick more to the friabilator. But, it can be said that the other formulations (M0.25, H1.5 and H2) are suitable for packaging.

Disintegration time was found to be in the range of 35 min and $120 \mathrm{~min}$. Since the lozenges are soft and chewable, their disintegration time is very long. Therefore typical disintegration times may not be achieved with these lozenges. In the United States Pharmacopeia (USP 35), the disintegration time of nystatin lozenges is 90 minutes [26]. Nystatin lozenges can be given as an example to this case. $\mathrm{H} 1.5$ and $\mathrm{H} 2$ formulations contain high amounts of bentonite. Since bentonite is a swelling material [17], it is primarily swollen in the lozenge, and in this case, it has made it difficult to disperse in artificial saliva.

Table 3. The evaluation parameters and results of bentonite included soft chewable lozenges

\begin{tabular}{lcccc}
\hline \multirow{2}{*}{ Evaluation Parameters } & \multicolumn{2}{c}{ Molding Technique } & \multicolumn{2}{c}{ Hand-rolling Technique } \\
\cline { 2 - 5 } & M0.25 & M0.5 & H1.5 & $4.82 \pm 0.06$ \\
Weight variation (g) & $5.85 \pm 0.19$ & $7.21 \pm 0.25$ & $4.02 \pm 0.02$ & $15.84 \pm 1.37$ \\
Diameter (mm) & $33.80 \pm 0.00$ & $26.53 \pm 0.28$ & $14.94 \pm 0.78$ & $15.39 \pm 1.04$ \\
Thickness (mm) & $5.65 \pm 1.41$ & $9.67 \pm 0.67$ & $17.61 \pm 0.96$ & 0.53 \\
Friability (\%) & 0.47 & 1.72 & 0.69 & 120 \\
Disintegration time (min) & 35 & 60 & 120 & \\
\hline
\end{tabular}

Table 4. The radiation absorption of bentonite included soft chewable lozenges

\begin{tabular}{lcccc}
\hline Radiation Absorption & \multicolumn{2}{c}{ Molding Technique } & \multicolumn{2}{c}{ Hand-rolling Technique } \\
\cline { 2 - 5 } & M0.25 & M0.5 & H1.5 & H2 \\
\hline $\begin{array}{l}\text { At the end of } \\
\text { the 6th hour (mCi) }\end{array}$ & $0.98 \pm 0.08$ & $1.01 \pm 0.16$ & $1.08 \pm 0.11$ & \multirow{2}{*}{$1.65 \pm 0.40$} \\
\hline
\end{tabular}

Table 5. Statistical analysis of bentonite included soft chewable lozenges

\begin{tabular}{|c|c|c|c|c|c|c|}
\hline & & \multirow{2}{*}{$\begin{array}{c}\text { Mean } \\
\text { Difference (I-J) }\end{array}$} & \multirow{2}{*}{ Std. Error } & \multirow{2}{*}{ Sig. } & \multicolumn{2}{|c|}{ Interval } \\
\hline & & & & & Lower Bound & Upper Bound \\
\hline \multirow[t]{3}{*}{$\begin{array}{l}\text { H2-At the end of } \\
\text { the 6th hour }\end{array}$} & $\begin{array}{l}\text { H1.5-At the end of } \\
\text { the } 6 \text { th hour }\end{array}$ & 0.57000 & 0.15871 & 0.004 & 0.2242 & 0.9158 \\
\hline & $\begin{array}{l}\text { M0.5-At the end of } \\
\text { the } 6 \text { th hour }\end{array}$ & 0.63500 & 0.15871 & 0.002 & 0.2892 & 0.9808 \\
\hline & $\begin{array}{l}\text { M0.25-At the end of } \\
\text { the } 6 \text { th hour }\end{array}$ & 0.66500 & 0.15871 & 0.001 & 0.3192 & 1.0108 \\
\hline
\end{tabular}




\subsection{Determination of Radiation Absorption}

The average radiation absorption efficiency of the lozenges containing bentonite was given at Table 4 . When the average amount of radiation per lozenge was examined, the highest dose of lozenges (H2) containing $2 \mathrm{~g}$ of bentonite showed the highest absorption and the results were significant $(p<0.05$, Table 5). As the amount of bentonite increased, the amount of radiation absorbed increased. In a study, bentonite was applied to patients with irritable bowel syndrome at a dose of $3 \mathrm{~g} 3$ times a day for 8 weeks and was found to be effective. There were no side effects from this dose. In our study, the highest dose was chosen as $2 \mathrm{~g}$ and it is thought to be a safe dose $[15,27]$.

It is written in the literature that bentonite is used for protection from radiation and studies on this subject are still ongoing. In Tanaka's study (2012), it clearly stated that the wastewater tanks were covered with bentonite to prevent the spread of radiation in the wastewaters of Fukushima Dai-ichi Nuclear Power Stations. It has also been stated that bentonite is used to fix/inhibit radioactive cesium (Cs) and the mobility of Cs in bentonite clay is about $3 \mathrm{~mm}$ for 300 years [28]. In Ishii's study, detailed information was given about the fact that the radioactive $\mathrm{Cs}$ in the vegetables produced in the Fukushima region is not found due to the dense clay content in the soil and this clay absorbs the radioactive Cs and that these vegetables are safely consumed [18]. Also, MartínezCostaa et al. concluded that, it was found that bentonite acts as a photocatalyst by absorbing UV and solar radiation and that radiation does not disrupt the crystal structure of clay [29]. Clays with high montmorillonite content protect RNA and RNA-like molecules from UV radiation was found in another study by Biondi et al [30]. Russian and Japanese scientists have regularly used bentonite to protect against radiation. Even after the Chernobyl disaster, bentonite chocolate and biscuits were distributed to the people of the region. After the Chernobyl disaster, the plant and its vicinity were covered with bentonite to minimize the negative effects of radiation. In Japan, hundreds of thousands of tons of clay was poured into the ocean in the Fukushima nuclear disaster caused by the earthquake [31]. So, the bentonite-containing lozenges we have prepared can help to remove radiation from the body.

\section{CONCLUSION}

In this study, lozenges containing bentonite were successfully prepared and characterization studies were carried out. In addition, the radiation absorption study was conducted and the effectiveness of bentonite in this formulation was evaluated. Radiation absorption increased significantly with the increase of the bentonite dose. This result has given us hope. The effectiveness of these lozenges in terms of absorbing radiation should be clarified with more detailed studies in the future. Nowadays, lozenges are preferred in chewable form and are easily used by many people due to their tolerable taste. Because of the ease of using the lozenges, it is thought that it may be useful and effective in radiation protection or removal of the exposed radiation from the body, especially for hospital workers who are frequently exposed to radiation and patients undergoing radiation therapy. It is foreseen that these workers or patients can chew these soft lozenges without any additional procedure such as drinking with water or injection.

\section{ACKNOWLEDGMENTS}

This study is produced from a undergraduate student's graduation thesis. The authors would like to thank Emrah ÖZAKAR for his kindly help in the study.

\section{CONFLICT OF INTEREST DECLARATION}

The authors report no conflict of interest. The authors alone are responsible for the content and the writing of the paper.

\section{FINANCIAL SUPPORT}

This study was financed by Ataturk University Scientific Research Project Foundation (BAP No: TLP-2019-7066).

\section{AUTHOR IDs}

RSÖ: Rukiye Sevinç Özakar

ORCID: 0000-0002-2972-8084

MK: Medya Kara

ORCID: -

AM: Adem Maman

ORCID: 0000-0002-7742-1028

\section{AUTHOR CONTRIBUTIONS}

Concept: RSÖ; Design: RSÖ; Supervision: RSÖ; Materials: RSÖ, MK, AM; Data Collection and/or Processing: RSÖ, MK, AM; Analysis and/or Interpretation: RSÖ, MK, AM; Literature Search: RSÖ, MK; Writing: RSÖ, MK; Critical Reviews: RSÖ, MK, AM.

\section{REFERENCES}

[1] Majekodunmi SO. A review on lozenges. Am J Med Sci Med. (2015); 5(2): 99-104. https://doi.org/10.5923/j.ajmms.20150502.07

[2] Choursiya S, Andheriya D. Review on lozenges. J Drug Deliv Ther. (2018); 8(6-A): 124-128.

[3] Allen LV. Troches and lozenges. Secundum Artem. (1998); 4(2): 23 25 .

[4] Umashankar MS, Dinesh SR, Rini R, Lakshmi KS, Damodharan N. Chewable lozenge formulation - A review. Int Res J Pharm. (2016); 7 (4): 9-16. https://doi.org/10.7897/2230-8407.07432

[5] Maheshwari R, Jain V, Ansari R, Mahajan SC, Joshi G. A review on lozenges. Br Med Bull. (2013); 1(1): 35-43.

[6] Pothu R, Yamsani MR. Lozenges formulation and evaluation: A review. Int J Res Pharm Res. (2014); 1(5): 290-298.

[7] Abdoun AS, Alenizi R. Formulation and evaluation of metronidazole lozenges for oral thrush. J Innov Pharm Biol Sci. (2019); 6(3): 5-10

[8] Thomas GA, Symonds P. Radiation exposure and health effects - Is it time to reassess the real consequences? Clin Oncol-Uk. (2016); 28(4): 231-236. https://doi.org/10.1016/j.clon.2016.01.007

[9] Gesell TF, Prichard HM. The technologically enhanced natural radiation environment. Health Phys. (1975); 28(4): 361-366. https://doi.org/10.1097/00004032-197504000-00006

[10] Choi TA, Costes SV, Abergel RJ. Understanding the health impacts and risks of exposure to radiation. In: Ahn J, Carson C, Jensen M, Juraku K, Nagasaki S, Tanaka S, editors. Reflections on the Fukushima Daiichi Nuclear Accident Springer, Cham; (2015). p. 259281. ISBN:978-3-319-12090-4

[11] Hager IZ, Rammah YS, Othman HA, Ibrahim EM, Hassan SF, Sallam FH. Nano-structured natural bentonite clay coated by polyvinyl alcohol polymer for gamma rays attenuation. J Theor Appl Phys. (2019); 13(2): 141-153. https://doi.org/10.1007/s40094-019-0332-5

[12] Aguzzi C, Cerezo P, Viseras C, Caramella C. Use of clays as drug delivery systems: Possibilities and limitations. Appl Clay Sci. (2007); 36(1-3): 22-36. https://doi.org/10.1016/j.clay.2006.06.015

[13] del Hoyo C, Vicente MA, Rives V. Preparation of drugmontmorillonite UV-radiation protection compounds by gas-solid adsorption. Clay Miner. (2001); 36(4): 541-546. https://doi.org/10.1180/0009855013640007 
[14] Bentonite, Kaolin, and Selected Clay Minerals Switzerland World Health Organization (2005).

[15] Moosavi M. Bentonite Clay as a natural remedy: A brief review. Iran J Public Health. (2017); 46(9): 1176-1183.

[16] Correcher V, Gomez-Ros JM, Garcia-Guinea J, Martin PL, Delgado A. Thermal stability of the thermoluminescence trap structure of bentonite. Radiat Prot Dosim. (2006); 119(1-4): 176-179. https://doi.org/10.1093/rpd/nci613

[17] Sellin P, Leupin OX. The use of clay as an engineered barrier in radioactive-waste management - A review. Clays Clay Miner. (2013); 61(6): 477-498. https://doi.org/10.1346/CCMN.2013.0610601

[18] Ishii K, Terakawa A, Matsuyama S, Hasegawa A, Nagakubo K, Sakurada T, Kikuchi Y, Fujiwara M, Yamazaki H, Yuhki H, Kim S, Satoh I. Measures against radioactive contamination due to fukushima first nuclear power plant accidents Part III: Removing and decontamination of contaminated soil. Int J Pixe. (2012); 22: 13-19. https://doi.org/10.1142/S0129083512400323

[19] How and Why to Drink Bentonite Clay (anti-radiation, detox, gut \& more). Retrieved April 12021 from

https://eatbeautiful.net/how-why-drink-bentonite-clay-radiationdetox/

[20] in Opportunities and Approaches for Supplying Molybdenum-99 and Associated Medical Isotopes to Global Markets: Proceedings of a Symposium. 2018: Washington (DC).

[21] Kumar A, Mishra MK, Afeefa, Chandrashekar KS, Pai G, Pai V. Development and evaluation of polyherbal lozenges for cold and flu. Indian J Pharm Educ. (2019); 53(2): 159-163. https://doi.org/10.5530/ijper.53.2s.61

[22] Abu Lila AS, Gomaa E, Ghazy FES, Hasan AA. Treatment of pulmonary arterial hypertension by vardenafil-solid dispersion lozenges as a potential alternative drug delivery system. J Drug Deliv Sci Tec. (2020); 55. https://doi.org/10.1016/j.jddst.2019.101444

[23] Modyala D, Aparna C, Srinivas P. Formulation, evaluation and characterization of itraconazole lozenges. Int J Pharm Biol Sci (2014); 9(3): 86-94. https://doi.org/10.9790/3008-09318694
[24] Koland M, Charyulu RN, Vijayanarayana K, Prabhu P. In vitro and in vivo evaluation of chitosan buccal films of ondansetron hydrochloride. Int J Pharm Investig. (2011); 1(3): 164-171. https://doi.org/10.4103/2230-973x.85967

[25] Bajelan E, Kamali-Nejad M, Foroutan SM, Albasha H. Formulation and physicochemical evaluation of lozenge tablets containing Salvia officinalis. J Young Pharm. (2014); 6(1): 34-38. https://doi.org/10.5530/jyp.2014.1.6

[26] USP30/NF25-The United States Pharmacopeia-National Formulary. USA: The United States Pharmacopeial Convention; (2007).

[27] Ducrotte P, Dapoigny M, Bonaz B, Siproudhis L. Symptomatic efficacy of beidellitic montmorillonite in irritable bowel syndrome: A randomized, controlled trial. Aliment Pharmacol Ther. (2005). 21(4): 435-444. https://doi.org/10.1111/j.1365-2036.2005.02330.x

[28] Tanaka S. Accident at the Fukushima Dai-ichi Nuclear Power Stations of TEPCO -Outline \& lessons learned-. Proceedings of the Japan Academy Series B-Physical and Biological Sciences. (2012); 88(9): 471-484.

[29] Martinez-Costa JI, Rivera-Utrilla J, Leyva-Ramos R, Sanchez-Polo $\mathrm{M}$, Velo-Gala I. Individual and simultaneous degradation of antibiotics sulfamethoxazole and trimethoprim by UV and solar radiation in aqueous solution using bentonite and vermiculite as photocatalysts. Appl Clay Sci. (2018); 160: 217-225. https://doi.org/10.1016/j.clay.2017.12.026

[30] Biondi E, Branciamore S, Maurel MC, Gallori E. Montmorillonite protection of an UV-irradiated hairpin ribozyme: evolution of the RNA world in a mineral environment. Bmc Evol Biol. (2007); 7. https://doi.org/10.1186/1471-2148-7-S2-S2

[31] Bentonit ile radyasyondan korunma - Chernobyl örneği. Retrieved April 12021 from

http://www.bentonittedavisi.com/bentonit/bentonit-ile-radyasyondankorunma-chernobyl-ornegi/ 